\title{
The Influence of Retinal Adaptation on the Electric Flicker Values
}

\author{
By \\ Koiti Miura \\ (三浦 孝 一) \\ From the Physiological Laboratory of Prof. K. Motokawa, \\ Tohoku University, Sendai
}

(Received for publication, November 27, 1957)

\section{INTRODUCTION}

It was reported by $\mathrm{Abe}^{1)}$, by Tsukahara \& $\mathrm{Abe}^{2)}$ and by Motokawa \& $\mathrm{Ebe}^{3)}$ that the alternating current of 20 c.p.s. might be the optimum frequency for electrical stimulation of the nervous tissue connected with rods.

According to $\mathrm{Abe}^{11}$, the time course of dark adaptation of the electrical excitability determined with the current of 20 c.p.s. was such that at first the threshold remained low and steady for about 5-7 minutes, and then increased rapidly to attain a maximum in about 17 minutes.

A similar time course of the electrical threshold was obtained also by Iwama ${ }^{4)}$ using a constant current pulse of about $50 \mathrm{msec}$.

Recently Mita et al..$^{5)}$ and Seto ${ }^{6)}$ obtained similar experimental results by using the sinusoidal alternating current of 20 c.p.s.

Barnett ${ }^{7)}$ interpreted a frequency of about 20 c.p.s. to be the optimum one for electrical stimulation of the cones, while the previous investigators ${ }^{1)-4}$ ) considered it as the resonance frequency for the rods.

In the present experiment, I studied the effect of adaptation on the electrical threshold of the eye for the alternating current of 20 c.p.s. with a view to contributing something to the question raised above.

\section{EXPERIMENTAL \\ Method}

The electric flicker value (F.V.) of the eye was measured with an apparatus which was manufactured by Toa Denpa \& Co. after Motokawa's suggestion. The detail of the design was explained in Motokawa's paper. $\left.{ }^{8}\right)$

A special use was made of the apparatus in the present experiment, as will be explained below.

As can be seen in Fig. 1, a key, which was missing in the original apparatus, was inserted into the output circuit in order to control the 


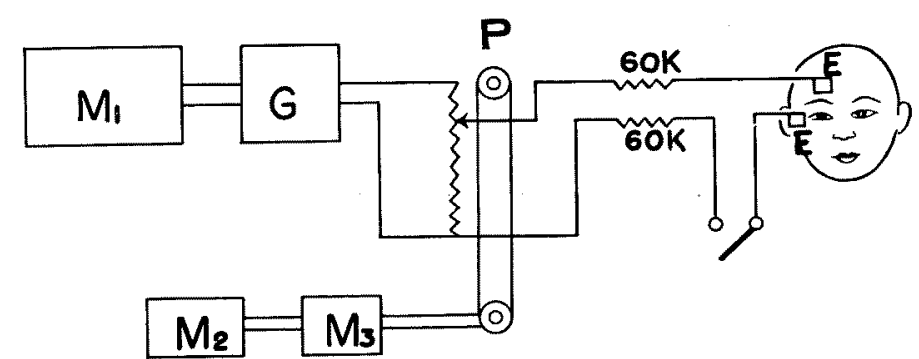

Fig. 1. Apparatus for measuring electric ficker value (F.V.) E : Stimulating electrodes. $G$ : Generator of alternating current of 20 c.p.s. $\mathbf{M}_{1}, \mathbf{M}_{2}$, $\mathrm{M}_{3}$ : Synchronous motors. $\mathrm{P}$ : Potentiometer whose electric contract is moved up and down by means of $\mathbf{M}_{2}$ and $\mathbf{M}_{3}$.

duration of stimulating current. The duration was fixed at $0.5 \mathrm{sec}$.

The F.V. was determined by the method of trial and error. It was referred to the threshold for disappearance of flicker ; the electrical stimulation which was started from a sufficiently high level was decreased in small steps of $3 \mu \mathrm{A}$. until any flicker was no more elicited.

The electrodes were placed on the forehead slightly above the eyebrow and on the homolateral temple. The electrical contact between the electrode and the skin was secured by electrode paste. The other eye was shielded. A patch of ground glass illuminated by tungsten lamps served for light adaptation. A collecting lens and an interference filter were used to produce colored light.

Daily variations of F.V. in my experiment are shown in Table I, which will give an idea of the accuracy in the present experiment.

\section{Results}

1) Changes of F.V. in the course of dark adaptation following light adaptation of 10 minutes to 9,800 lux ( $D$-curve)

F.V. was measured in the course of dark adaptation. An example of the results obtained is illustrated in Fig. 2. After 1 min., the F.V. was lowest, and there was no significant rise yet after $3 \mathrm{~min}$. Then it increased slowly till about $8 \mathrm{~min}$. after the onset of darkness, and increased thereafter rapidly to attain a maximum in about $15 \mathrm{~min}$.

This course is almost the same as in the previous papers cited above.

2) F.V.-time curves obtained during continuous illumination with white light of a small retinal area following the same light adaptation as above

In this experiment, a small retinal area at the fovea, $5^{\circ}, 10^{\circ}$ or $20^{\circ}$ from the fovea was continuously exposed to white light of 30 lux. The patch used was a circle of $40^{\prime}$ in visual angle.

The curves obtained are illustrated in Fig. 3. The F.V.-time curve 
Adaptation and Electric Flicker

TAB LE I

Daily Variations of F.V.

\begin{tabular}{|c|c|c|c|}
\hline & \multirow{2}{*}{ Session } & \multicolumn{2}{|c|}{ F.V. in $\mu \mathrm{A}$} \\
\hline & & $8^{\prime}$ after onset of darkness & $20^{\prime}$ after onset of darkness \\
\hline 1 & $\begin{array}{l}\text { a.m. } 8.00 \\
\text { Noon } \\
\text { p.m. } 5.00\end{array}$ & $\begin{array}{l}24 \\
24\end{array}$ & $\begin{array}{l}54 \\
60 \\
60\end{array}$ \\
\hline 2 & $\begin{array}{l}\text { a.m. } 8.00 \\
\text { Noon } \\
\text { p.m. } 5.00\end{array}$ & $\begin{array}{l}27 \\
21\end{array}$ & $\begin{array}{l}57 \\
63 \\
57\end{array}$ \\
\hline 3 & $\begin{array}{l}\text { a.m. } 8.00 \\
\text { Noon } \\
\text { p.m. } 5.00\end{array}$ & $\begin{array}{l}24 \\
24\end{array}$ & $\begin{array}{l}60 \\
57 \\
60\end{array}$ \\
\hline 4 & $\begin{array}{l}\text { a.m. } 8.00 \\
\text { Noon } \\
\text { p.m. } 5.00\end{array}$ & $\begin{array}{l}21 \\
24\end{array}$ & $\begin{array}{l}57 \\
54 \\
63\end{array}$ \\
\hline 5 & $\begin{array}{l}\text { a.m. } 8.00 \\
\text { Noon } \\
\text { p.m. } 5.00\end{array}$ & $\begin{array}{l}24 \\
27\end{array}$ & $\begin{array}{l}57 \\
60 \\
60\end{array}$ \\
\hline Aver & $\begin{array}{l}\text { ge \& standard } \\
\text { deviation }\end{array}$ & $24.0 \pm 1.89$ & $58.6 \pm 2.65$ \\
\hline
\end{tabular}

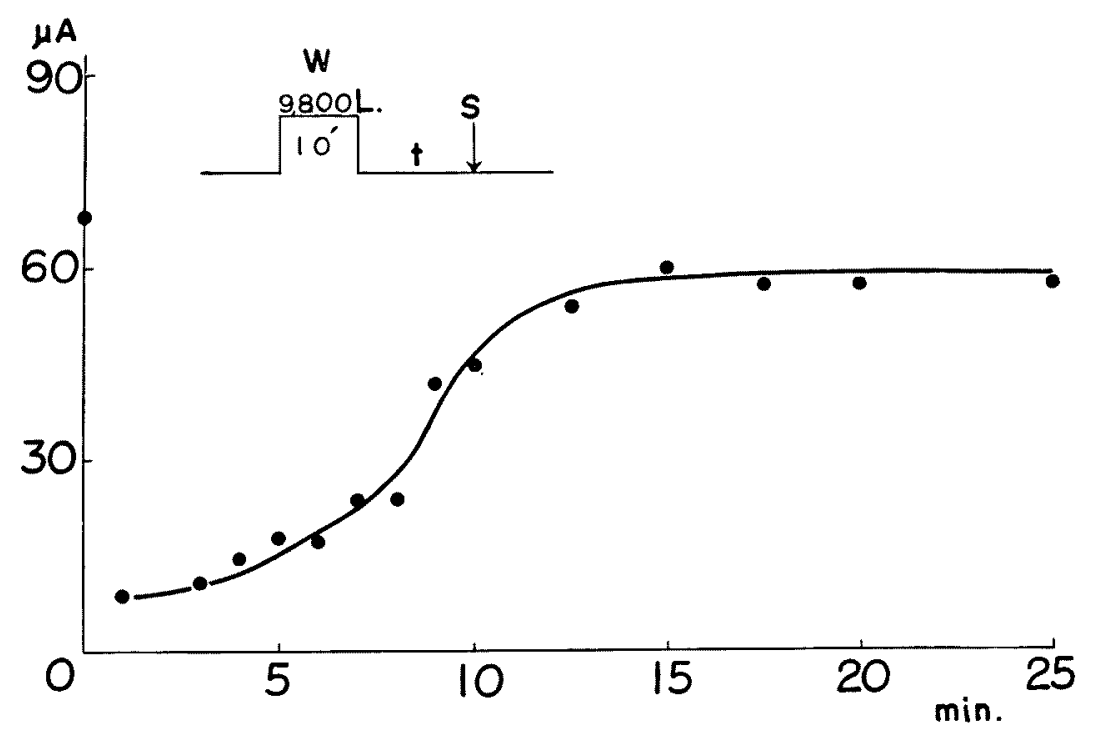

Fig. 2. F.V.-time curve during the course of dark adaptation. Ordinates : F.V. in fA. Abscissae: Time from onset of darkness in min.

obtained by illumination of the fovea ran the same time course as the D-curve obtained above in the complete darkness at its initial stage till 8 


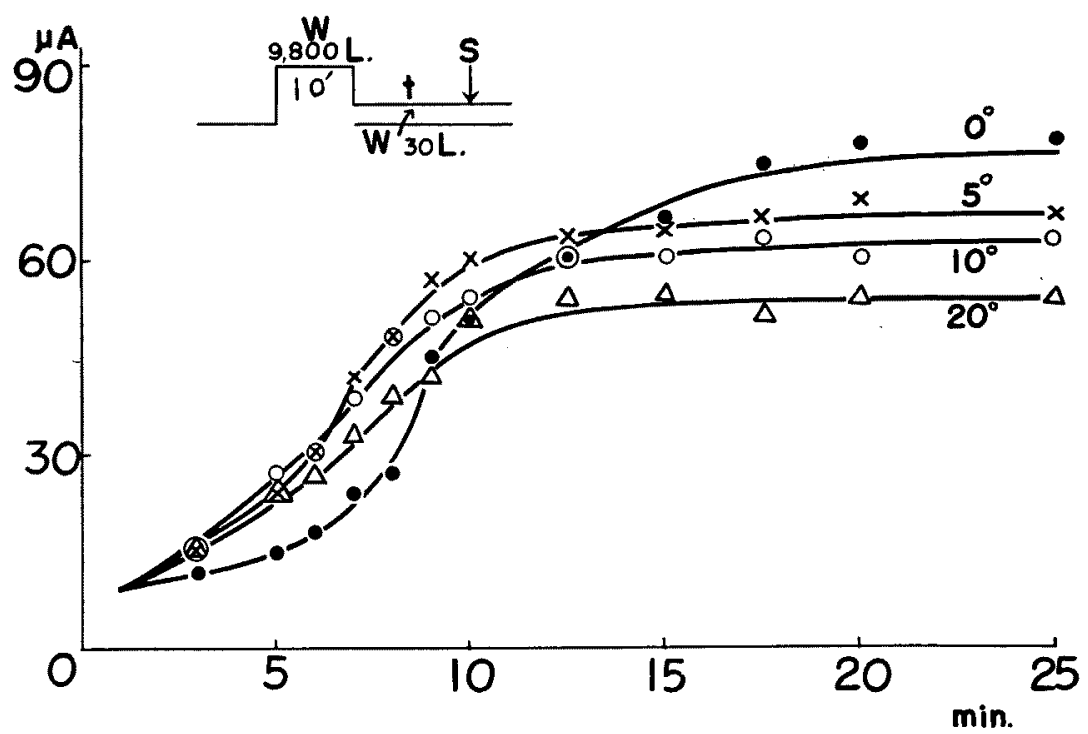

Fig. 3. F.V.-time curves obtained continuous local illumination of a small area of retina with white light of 30 lux following light adaptation. $0^{\circ}$, $5^{\circ}, 10^{\circ}$ and $20^{\circ}$ represent eccentricity from the fovea.

minutes, and then rose to a higher level of threshold than the $\mathrm{D}$-curve at the later stage. It is to be noted that the inflection at about 8 minutes is very conspicuous. Such an inflection is, however, only slight or missing in the other curves obtained at the peripheries.

Generally speaking, the curves for the peripheries reach a steady level earlier than the $\mathrm{D}$-curve.

The most characteristic feature is that the farther the location of illumination was moved towards the periphery from the fovea, the lower the steady level of threshold.

3) F.V.time curves obtained during continuous exposure of a small retinal area to colored light following the same light adaptation as above

A circular patch of $40^{\prime}$ in visual angle was used for continuous illumination, whose illumination was 50 lux without filter.

In Fig. 4, the curves connecting solid circles represent those obtained by illumination of the fovea, and the curves connecting empty circles those obtained by illumination of a peripheral area $40^{\circ}$ from the fovea.

As can be seen in Fig. $4 \mathrm{a}$ and b, when blue light $(452 \mathrm{~m} \mu)$ and green light $(505 \mathrm{~m} \mu)$ were used, the two curves referring to the fovea crossed with those obtained by illumination at the periphery about 10 minutes after the onset of dark adaptation. The steady level is much lower at the periphery than at the fovea, the difference is especially conspicuous for 


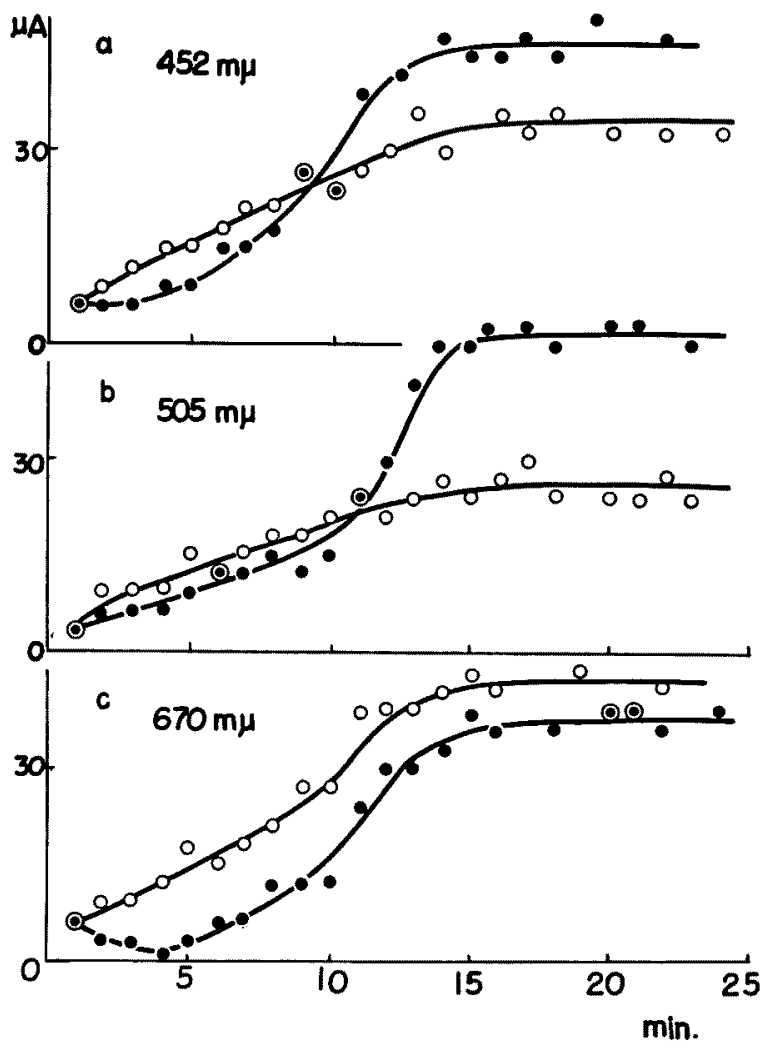

Fig. 4. F.V.-time curves obtained during continuous local illumination of a small area ( $40^{\prime}$ in visual angle) of retina with colored lights following light adaptation. Curves connecting solid circles refer to illumination at fovea, and curves maked by empty circles to illumination at periphery $40^{\circ}$ from fovea.

green light.

The contrary result is seen in Fig. $4 \mathrm{c}$. When the red light $(670 \mathrm{~m} \mu)$ was used, the curve obtained at the fovea was found to run below the curve obtained at the periphery, and the steady level for the foveal curve was also lower in contrast with the other cases.

4) F.V.-time curves obtained during continuous illumination with white light of a great retinal area following the same light adaptation as above

In this experiment, following the preliminary light adaptation to 9,800 lux the intensity of adapting light was adjusted to 1,000 lux, 100 lux, 10 lux, 1 lux or 0.1 lux, and F.V.-time curves were obtained for each secondary exposure (Fig. 5). For comparison the D-curve is represented by a broken curve.

As can be seen in this figure, there was almost no elevation of threshold 


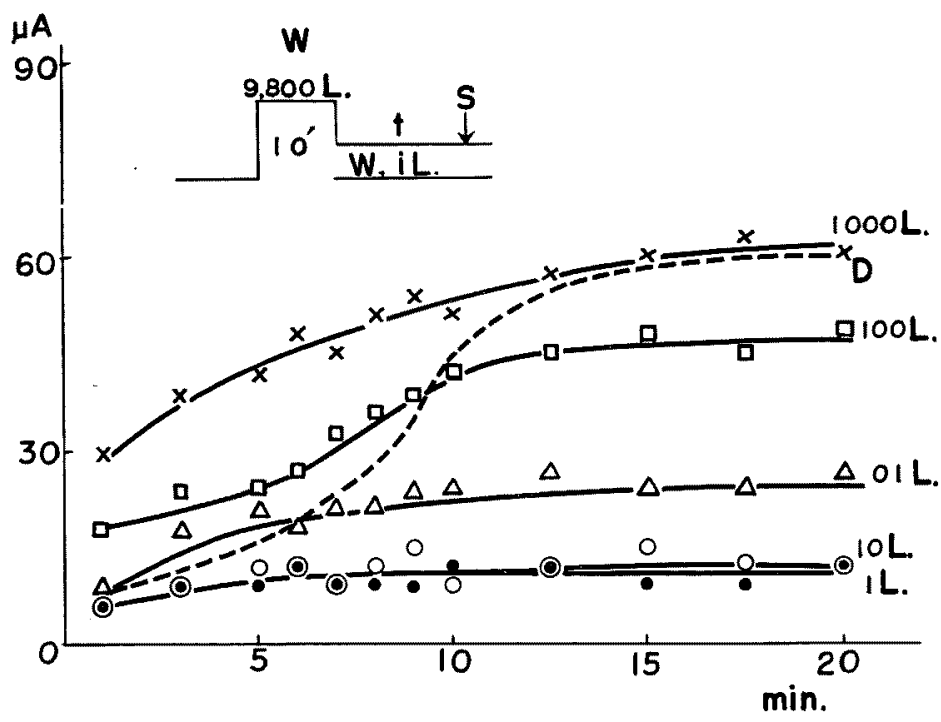

Fig. 5. F.V.-time curves obtained during continuous illumination of a great area ( $120^{\circ}$ in visual angle) of retina with white light of various intensities following light adaptation.

in the two curves obtained by exposure to 1 lux and 10 lux. These two curves were lower than the D-curve. There was a slight increase in the curve obtained by illumination with 0.1 lux. As for the curve for 100 lux the threshold at the initial stage was higher than the D-curve, but the final level was lower than it.

\section{Discussion}

Abe ${ }^{1)}$ determined the F.V.-time curve of the human eye under experimental conditions similar to the present experiment, except for the intensity of adapting light; it was 24,000 lux, that is, higher than in the present experiment. He states that at first the threshold remained low and steady for about 5-7 minutes, and then increased rapidly to attain a maximum in about 17 minutes, but made no graphical representation. Abe's result ${ }^{1)}$ agrees well with my D-curve; a small difference in time required to reach the final steady value depends probably on the difference of the pre-illuminating intensity. The time to reach the final steady value was found to be about 10 minutes, in Seto's experiment ${ }^{7)}$, in which the intensities of adapting light were only 1,000 and 5,000 lux. There is no essential difference between the D-curve and those obtained by Iwama ${ }^{4}$, Mita $^{5}$, Seto ${ }^{6}$, although experimental conditions were not identical.

The rapid increase of threshold as is seen at the middle stage of those curves was ascribed by $A \mathrm{Ab}^{11}$ to the dark adaptation of the rods. This 
interpretation is supported by the fact that under continuous illumination confined to the fovea, the inflection at the middle stage is especially conspicuous (see the curve $0^{\circ}$ in Fig. 3). It is because the dark adaptation of the retinal periphery is not disturbed by foveal illumination. In such interpretation it is assumed that excitation of visual cells, especially rods and in consequence increased activity of the nervous system concerned will lead to a lowering of electrical threshold as measured by the present method. The inflection of the curve disappears when the dark adaptation of the rod is disturbed by peripheral illumination of the retina (see curve $5^{\circ}, 10^{\circ}$ and $20^{\circ}$ in Fig. 3). The fact that the final threshold becomes lower as a farther periphery is illuminated, can well be understood from this point of view. No inflection can be seen in the curves for the light of optimum wave-lengths to stimulate the rods, and the final thresholds are very low (see Fig. $4 \mathrm{a}$ and b). On the contrary a very conspicuous inflection can be seen in the curve for red light which does not excite the rods (see Fig. $4 \mathrm{c})$.

Moreover, the F.V.-time curve obtained during the secondary illumination with 10 lux-0.1 lux which may be regarded as exciting the rods optimally, showed no inflection and their final thresholds were very low (see Fig. 5).

The values of the final thresholds of those curves illustrated in Fig. 5 are very near the value of thresholds in strength-log illumination curves reported by Takahashi ${ }^{9}$.

About the earlier stage of the F.V.-time curve, it may be supposed that the responses of the cones and the elements connected with them are responsible for electrical thresholds, because the threshold at this stage was found very low when the fovea was illuminated by the red light.

\section{SumMary}

The electrical threshold of the eye was measured by the alternating current of 20 c.p.s. with flicker sensation caused by it as an index under various adaptation states.

1. The threshold-time curve during complete dark adaptation following light adaptation of 10 minutes to illumination of 9,800 lux shows the following course: At first the threshold remained low for about 8 minutes, and then increased rapidly to attain a constant level in about 15 minutes. Thus, the curve showed an inflection at about 8 minutes.

2 . The curve suffered from a modification when the retina was constantly exposed to a small point of light of $40^{\prime}$ in visual angle following the same light adaptation as above.

The inflection at the middle stage became more obscure and the final level lower as local illumination was moved farther towards the periphery 
of the retina.

3. The effect of similar local illumination was investigated with colored lights.

When blue, green and red lights were used for local illumination, it was found that the red light showed an effect similar to white light confined to the fovea, but that the green and blue light acted as white light illuminating the periphery of the retina.

4. Next the effect of exposure to broad illumination was investigated upon the curve following the same light adaptation as above.

The curves by illumination of 0.1 lux, 1 lux and 10 lux were low and almost steady, but those by 100 and 1,000 lux were generally much higher.

From these experiments it is likely that the threshold as determined by the A.C. of 20 c.p.s. is lowered when visual cells, especially rods are excited to some extent.

I am greatly indebted to Prof. Motokawa for his many valuable discussions and kind guidance.

\section{References}

1) Abe, Z., Tohoku J. Exp. Med., 1951, 54, 37.

2) Tsukahara, S. \& Abe, Z., ibid., 1951, 54, 193.

3) Motokawa, K. \& Ebe, M., J. Opt. Soc. Amer., 1953, 43, 203.

4) Iwama, K., Tohoku J. Exp. Med., 1949, 50, 71.

5) Mita, T., Fujimaki, E. \& Yaegashi, S., Tohoku J. Exp. Med., 1956, 65, 45.

6) Seto, Y., Acta Soc. Ophth. Jap., 1957, 61, in press.

7) Barnett, A., Amer. J. Physiol., 1949, 133, 205.

8) Motokawa, K., Umetsu, J., Kobayashi, M. \& Kameyama, M., Tohoku J. Exp. Med., $1956,61,151$.

9) Takahashi, R., Acta Soc. Ophth. Jap., 1954, 58, 831. 